\title{
EFFECTS OF AFFILIATIVE AND AGGRESSIVE HUMOR ON CREATIVE THINKING
}

\author{
Md Shahinoor Rahman ${ }^{*}$, Zhou Zhijin ${ }^{1}$ and Muhammad Kamal Uddin ${ }^{2}$ \\ Department of Psychology, University of Chittagong, Chittagong, Bangladesh
}

\author{
Key words: Aggressive humor, Affiliative humor, Convergent thinking, Divergent \\ thinking
}

\begin{abstract}
Previous correlational studies suggest that negative humor style such as aggressive humor style is negatively and positive humor style such as affiliative humor style is positively correlated with creativity. However, it is not yet to experimentally demonstrate the effect of aggressive and affiliative humor on creativity. Therefore, this experimental study was designed to investigate the effect of affiliative humor (AF) and aggressive humor (AG) on creative thinking. The researcher included 60 (38 male, 22 female) participants and randomly assigned 20 in each of AF, AG, and control conditions. To induce humor, theyused12 jokes in each condition. They used Remote Association Task (RAT) for convergent thinking and Alternative Use of task (AUT) for divergent thinking to measure individual creativity. The author expected that (i) people who engage in affiliative humor would perform better at convergent thinking tasks than the control group and the aggressive humor group, (ii) people who engage in affiliative humor would perform better at divergent thinking tasks than the control group and aggressive humor group. Results showed that the affiliative humor successfully induced convergent thinking better than the control group and aggressive humor in the RAT score. Similarly, AF humor successfully induced better creativity than the control group and AG humor group in three components of divergent thinking; fluency, flexibility, and elaboration. However, the mean score of AF humor was better than the AG humor group but not significant. In addition, aggressive humor, likewise affiliative humor, also induced creative thinking in the RAT task and AUT. Thus, the results partially supported all the hypotheses and indicated that in real life, humor induces individual creative thinking whether the humor is positive or negative, it doesn't matter. Both types of humor increase creative thinking.
\end{abstract}

\section{Introduction}

Creativity is defined as the generation of ideas that are new yet appropriate to the norms ${ }^{(1)}$. The theory of intellect gave importance to two types of daily creativityconvergent and divergent thinking( ${ }^{(2)}$. In daily life and the business world, creativity is essential. Creativity plays a crucial role in everyday life settings such as home, schools,

*Author for correspondence: <shahinpsy@cu.ac.bd>. 1School of Psychology, Central China Normal University, PR China. ${ }^{2}$ Department of Psychology, University of Dhaka, Dhaka-1000, Bangladesh. 
classrooms, classrooms, and social settings ${ }^{(3)}$. Creative performance is also vital for the economic, scientific, and business world that work as a driving force of innovation ${ }^{(4 ; 5)}$. Innovation is the cornerstone of a business and the economy. Thus, enhancing creativity is important for our daily life to business life. In this experiment, the researcher included two types of creative thinking; divergent and convergent.

Humor refers to a cognitive experience evoked by quality of action, speech or writing, picture, or event that produced amusement, enjoyment, laughter/smile due to incompatibility of our expectation. There is four style humor explained by Martin et al.(6), among them two of which were self-focused (intrapersonal) and two of which were other-focused (interpersonal) humor. This current study used two types of other-focused (interpersonal) humor, affiliative and aggressive humor. Affiliative humor refers to the tendency to use non-hostile, funny, harmless silly jokes to make fun of the other and engage in spontaneous, witty banter in order to amuse others. This humor is positively related to effectiveness and playfulness ${ }^{(7)}$. On the other hand, aggressive humor refers to the tendency to use humor to criticize others by irony, sarcasm, teasing, mockery, ridicule, or silly funny jokes. This types of humor is related to grotesque or macabre character, cleverness, and wordplay ${ }^{(8)}$.

Humor and creativity both violate the existing norm and have similar consequences $^{(9)}$. Humor is one of the facilitating factors for creativity ${ }^{(10)}$. So, there is a link between humor and creativity which was confirmed by several researchers ${ }^{(11 ; 12)}$. So, humor enhances creativity but does all type of humor have a same enhancing effect on creativity? Positive humor style positively and negative humor style is negatively related to creativity ${ }^{(12 ; 13)}$. Thus, different form of humor would have different types of effects on creativity.

Literature showed other related humor types such as affiliative humor and aggressive have a mixed relationship with creativity. One researcher found that affiliative humor is unrelated to creativity, although most of the researchers found that affiliative humor associated with creativity. One researcher found employees' creativity was not related to affiliative humor ${ }^{(14)}$. Contrary, two recent studies have found that employee creativity was related to affiliative humor. For example, Amjed and Tirmzi(15) found that affiliative humor was positively related to employee creativity, and Masih et al. ${ }^{(16)}$ found that leaders' affiliative humor was associated with followers' creativity.

Similarly, Lussiera et al.(11) found that affiliative humor was positively related to creativity, and Kocak ${ }^{(17)}$ identified affiliative humor was positively related to academics' creativity. Moreover, Yue and Hui ${ }^{(18)}$ found affiliative humor was positively correlated with creative personality traits, whereas Chang et al. (12) found affiliative humor was not related to creative potential but positively related to divergent feelings, flexibility, creative attitude. So, affiliative humor is positively related to academics' creativity, divergent thinking (flexibility), divergent feeling, creative attitude, and creative 
personality, but there is a confusing relationship with employee creativity and no relationship with creative potential.

The relationship between aggressive humor and creativity is still confusing. Few researchers claimed aggressive humor was negatively associated with creativity, but even fewer claimed aggressive humor has no relationship with creativity. For example, Kocak ${ }^{(17)}$ identified that aggressive humor was negatively related to academics' creativity, divergent thinking, and creative attitude. In two other studies, Cayirdaga and Acarb(19) found that aggressive humor style was negatively related to divergent thinking; fluency, originality, and creativity index, and Chang et al.(12) found that aggressive humor was negatively associated with divergent feelings and creative attitude. But Chang and his associate also identified that aggressive humor was not related to creative potential. Similarly, later, Yonatan-Leus, Tishby, Shefler, and Wiseman (2017) also found that aggressive humor style was not related to therapist creativity. Two studies have shown likewise, therapist creativity, that aggressive humor was not linked with employee creativity. For example, Deog-Rolee ${ }^{(14)}$ found the leader's aggressive humor was not related to employee's creativity, and Amjed and Tirmzi ${ }^{(15)}$ found no relationship between aggressive humor and employee creativity. Finally, Yue and Hui ${ }^{(18)}$ found that aggressive humor was not related to creative thinking abilities, even they found aggressive humor was positively associated with creative personality traits(novelty). An aggressive humor style is negatively related to academic creativity, divergent feeling, divergent thinking (fluency, originality), creative attitude, and creative potential but not associated with therapist creativity, employee creativity, and creative thinking abilities. Interestingly, aggressive humor type is positively related to creative personality traits (novelty).

Literatures clearly showed that the relationship between other-related humor (affiliative, aggressive) type and creativity is still confusing. Furthermore, no study till date has been done that directly investigated the causal effect of two types of humor, affiliative and aggressive, on creativity in experimental settings. Thus, the purpose of this study is to examine the causal effect of two types of other-related humor (affiliative and aggressive) on individual creativity (divergent and convergent thinking) among Bangladeshi students. To investigate the effect, researchers demonstrated this study, and this study would fill some gaps in this area.

Rationale of this study: The findings of this study provide some theoretical and practical implications. In theoretical implication, this finding contributed to the literature extending the previous correlation research in an experimental setting that confirms that other related humor types have different impacts on individual creativity. In practical implication, this study's findings may be helpful for promoting creativity in various organizations, institutions, and government agencies. In education, the teacher may learn how to use humor appropriately. A teacher can use affiliative or aggressive humor to promote creativity to the student. In an organization and government agency, the 
authority manager or a leader may use affiliative humor or aggressive humor to encourage creative performance in the employee creativity.

The objective of the study was to investigate the effect of affiliative and aggressive humor on convergent and divergent thinking.

\section{Hypothesis:}

$\mathrm{H}_{1}$ : People who engage in affiliative humor would perform better at convergent thinking than people who engage in aggressive humor or no humor.

$\mathrm{H}_{2}$ : People who engage in affiliative humor would perform better at divergent thinking than people who engage in aggressive humor or no humor.

\section{Materials and Methods}

Participants: Participants were invited to participate in a psychological experiment from different faculties and departments via their notice board and personal contact. Interested participants who contacted the researcher to participate were included randomly in this experiment. A total of 60 undergraduates (38 males and 22 females) from Chittagong University were finally included in this study. Their average age was $21.70 \pm 1.71$ years old. Participants were randomly assigned to one of three conditions with the type of humor (affiliative humor, aggressive, no-humor) serving as a betweensubjects factor.

Research design: A single factor, the three-level between-subject design, was used in this study. The independent variable was different types of humor and non-humor materials (affiliative, aggressive humor, non-humor). The dependent variable was chosen to be the accuracy of association word in Remote Association Task (convergent thinking) and produce Alternative thinking task (divergent thinking).

Consent form: The consent form was provided to the participants prior to the study to ensure that subjects understood the study's voluntary and anonymous nature and the possibility to withdraw from the study at any time (yet before the data collection). The consent form briefly described the procedure and addressed possible risks and discomforts to the participants. Moreover, researchers gave participants with appropriate contact numbers and email addresses in case they needed more information about the study or seek additional help or advice after the experiment.

Demographic information: The first section of the questionnaire aimed to obtain the basic demographic information about the participants, such as their gender, age, native language, and educational background.

Sense of humor scale (SHS): Bengali version of Svebak's(20) sense of Humor Questionnaire was used to measure the level of humor of the subjects to control their impact on the results of the study. The scale consists of six items, with a four-point Likert-type response from 1 to 4 , and its score range is 6 to 24 . The higher the score, the 
higher is the level of humor. The Bengali version of this scale was translated and adapted by the researcher.

Convergent thinking: Researchers used the Remote association task (RAT) to measure convergent creativity, originally developed by Mednick ${ }^{(21)}$. In the remote association task, three words were presented, and the participant was required to identify the (fourth) word that connects these three seemingly unrelated words (e.g., "bass, complex, sleep" where the solution is "deep"). In this experiment, researchers assigned 15 Bengali RAT tasks to the participants, and all the Bengali RAT tasks were standardized in a pilot study on 70 students who did not participate in this experiment. All the test solution word items were a remote, uncommon associate of each stimulus word, requiring the respondent to work outside of the common analytical constraints. The score was determined by the number of valid answers given within a particular time.

Divergent thinking: Guilford's(2) Alternative Uses Task(AUT) was used to measure creativity in this study. Participants were asked to list as many possible uses for a "pen" and a "sock" within 3 minutes in this task. Scoring was comprised of four components: (i) originality- The number of unusual and unique ideas were used to calculate the originality score of each participant, only $5 \%$ responses of the group count as unusual (1 point), and only $1 \%$ responses of the group count as unique ( 2 points), (ii) Fluency-The number of ideas used to calculate the fluency score of the participant, (iii) flexibility- The number of different categories used to calculate the flexibility score of the participant. Finally and (iv) elaboration-The amount of detailed ideas used to calculate the elaboration score of the participant.

Humorous materials: Two types of humorous stimuli were used in this study. One was affiliative humor jokes, and the other one was aggressive humor jokes. A total of 40 (21 males and 19 females) participants ranging in age from 16 to $23(19.60 \pm 2.84)$ years old were included in a pilot study to develop those humorous materials. Respondents classified the stimuli and rated the degree of comprehensibility and funniness on a 9point scale, with a higher score indicating a higher degree. The overall average of funniness for humor was $6.93 \pm 1.04$, indicating that humor materials successfully produce amusement to the participants. Nonparametric Kruskal-Wallis one-way analysis of variance by ranks tests was performed on the funniness ratings for the two types of humor and the non-humor conditions. Funniness ratings were significantly different across the three conditions, $\chi^{2}(2)=18.25, \mathrm{p}<0.001$. A post hoc test showed that the two humor conditions were significantly funnier than the non-humor condition. In the current experiment, researchers used 12 jokes as priming materials in each humor condition, and in the non-humorous condition, theyused 12 non-humorous statements as the stimulus. Before presenting humorous and non-humorous materials, each participant was engaged with the following scenario. 
"Imagine that one day at work, your boss gives you a task to solve a problem discussing with a colleague. Your colleague greets you and takes you to two other team members sitting in the row in front of you. Before the discussion begins, the four of you start a conversation about how to solve the problem".

For affiliative humor condition, this section read -

"At one point, the casual colleague starts telling several funny jokes about your abilities and daily life in order to put you up or praise you."

For aggressive humor condition, this section read-

"At one point, the casual colleague starts telling several funny and silly jokes that ridicule your abilities in order to put you down."

Finally, for non-humorous condition below section read:

"At one point, your colleague starts telling several non-humor statements about you."

Procedure: The following procedures were followed sequentially in this experiment. First of all, interested participants were asked to complete consent form with demographic information. Following that, a sense of humor questionnaire was given to the participants to assess their sense of humor level. Next, based on their sense of humor, participants were randomly assigned to experimental and control conditions. In the affiliative humor condition, participants were shown 12 affiliated humor jokes, whereas in the aggressive humor condition, participants were shown 12 aggressive humor jokes. In the control condition, participants were shown only non-humorous statements instead of jokes, which were also rated as non-humorous by students in a pilot study. Following the presentation of the stimulus, participants were given Remote Association Task (RAT) and Guilford's Alternative Uses Task (AUT). After finishing the task, they were thanked for their participation in this study and said goodbye with a small gift. Each participant was shown jokes on an HP 17inch monitor screen perform by using e-prime. In each trial, a participant was shown a story +12 jokes one by one on the monitor. In the remote association task, participants were given Bangla 15 RAT tasks to perform, where each task was shown for the $50 \mathrm{~s}$ and fixation point for $250 \mathrm{~ms}$, followed by a black screen for $250 \mathrm{~ms}$. In the alternative use of task, a participant was shown two objects and gave 3min to write alternative ideas for each object.

Manipulation check: Few manipulations checks were used in this experiment. First of all, to control participant's sense of humor, Svebak's six-item Sense of Humor Questionnaire was used in this experiment, which indicated that all the participants had a high sense of humor on this scale. Second, after watching jokes in each category, each participant was asked to rate the overall amusement level of the stimuli on a scale of 1 to 9. In this rating, the Affiliative humor and Aggressive humor average rating scores were $7.0 \pm 0.70$ and $6.70 \pm 1.05$, respectively. A participant with a score of less than five was not considered for this experiment. Finally, to counterbalance the sequential effect of RAT 
and AUT after the presentation of a humorous stimulus, half of the participants performed RAT first, then AUT task and the remaining participants performed AUT task first, then RAT task.

Analysis: Data was inputted and analyzed with the help of SPSS 25.0 software. Oneway Analysis of Variance (ANOVA) and t-test were employed in this study to find out the effect of affiliative and aggressive humor.

\section{Results and Discussion}

The performance of the RAT and scores of AUT was good and shown in Table 01. The one-way analysis of variance (ANOVA) of affiliative and aggressive humor types, RAT and AUT, are shown in Table 2.

Convergent thinking: The results of one-way analysis of variance among three conditions of affiliative humor, aggressive humor, and non-humor condition was significant, $\mathrm{F}(2,57)=8.58, \mathrm{p}<.01$. Independent samples t-test indicated that Remote Association Task (RAT) scores of affiliative humor $(\mathrm{M}=7.35, \mathrm{SD}=1.87)$ was significantly higher than non-humorous $(M=4.85, S D=1.59)$ condition $(38)=4.66, \mathrm{p}<0.01$. Similarly, RAT score of aggressive humor $(M=6.15, S D=2.27)$ was significantly higher than nonhumorous $(\mathrm{M}=4.85, \mathrm{SD}=1.59)$ condition, $\mathrm{t}(38)=2.09, \mathrm{p}<0.05$. Finally, it was found that there was no significant difference between affiliative and aggressive humorous conditions, $\mathrm{t}(38)=1.85, \mathrm{p}>0.05$. Therefore, it can be summarized that the humorous groups significantly differ from the non-humorous condition in terms of convergent creative thinking. In other words, both affiliative and aggressive humor significantly increased creative thinking when compared to non-humorous conditions. In humor conditions, affiliative humor has a slightly higher RAT score than aggressive humor, but the difference is not statistically significant.

Table 1. Statistic of Remote association task (RAT) and Alternative use of task (AUT) of nonself-involvement humor.

\begin{tabular}{llllll}
\hline \multirow{2}{*}{$\begin{array}{l}\text { Independent } \\
\text { variable }\end{array}$} & $\begin{array}{l}\text { Convergent Thinking } \\
(\mathrm{RAT}) \mathrm{M}(\mathrm{SD})\end{array}$ & \multicolumn{4}{c}{ Divergent thinking (AUT) } \\
\cline { 3 - 6 } & & $\begin{array}{l}\text { Originality } \\
\mathrm{M}(\mathrm{SD})\end{array}$ & $\begin{array}{l}\text { Fluency } \\
\mathrm{M}(\mathrm{SD})\end{array}$ & $\begin{array}{l}\text { Flexibility } \\
\mathrm{M}(\mathrm{SD})\end{array}$ & $\begin{array}{l}\text { Elaboration } \\
\mathrm{M}(\mathrm{SD})\end{array}$ \\
\hline Non-humor & $4.85( \pm 1.59)$ & $2.65( \pm 1.49)$ & $4.95( \pm 1.93)$ & $4.65( \pm 1.89)$ & $4.55( \pm 2.48)$ \\
AF humor & $7.35( \pm 1.78)$ & $5.35( \pm 2.85)$ & $7.75( \pm 1.65)$ & $6.95( \pm 1.76)$ & $8.30( \pm 3.20)$ \\
AG humor & $6.15( \pm 2.27)$ & $4.95( \pm 2.08)$ & $6.70( \pm 1.49)$ & $6.35( \pm 1.46)$ & $7.50( \pm 3.39)$ \\
\hline
\end{tabular}

$\mathrm{AF}=$ Affiliative humor, $\mathrm{AG}=$ Aggressive humor.

Divergent thinking:The results of one-way analysis of variance among three conditions of affiliative humor, aggressive humor, and non-humor condition found a 
significant effect on four components of divergent thinking; originality, fluency, flexibility, and elaboration.

Firstly, the significant variance of originality was, $\mathrm{F}(2,57)=8.64$, p $<0.01$; post-hoc test revealed that affiliative humor $(\mathrm{M}=5.35, \mathrm{SD}=2.85)$ and aggressive humor $(\mathrm{M}=4.95$, $\mathrm{SD}=2.08)$ both significantly produced more original ideas than non-humor $(\mathrm{M}=2.65, \mathrm{SD}$ $=1.49$ ) condition. Next, the significant variance of fluency was, $F(2,57)=13.83, \mathrm{p} \varangle 0.01$; post-hoc test revealed that affiliative humor $(\mathrm{M}=7.75, \mathrm{SD}=1.65)$ and aggressive humor $(\mathrm{M}=6.70, \mathrm{SD}=1.49)$ both significantly produced more ideas fluency than non-humor ( $\mathrm{M}$ $=4.95, \mathrm{SD}=1.93)$ condition. Thirdly, the significant variance of flexibility was, $\mathrm{F}(2,57)=$ 9.65, $\mathrm{p}<0.01$; post-hoc test showed that affiliative humor $(\mathrm{M}=6.95, \mathrm{SD}=1.76)$ and aggressive humor $(\mathrm{M}=6.35, \mathrm{SD}=1.46)$ both also produced more flexible ideas than nonhumor $(\mathrm{M}=4.65, \mathrm{SD}=1.89)$ condition. Finally, similarly, the significant variance of elaboration was, $\mathrm{F}(2,57)=8.29, \mathrm{p}<01$; post-hoc test exposed that affiliative humor $(\mathrm{M}=$ $8.30, \mathrm{SD}=3.20)$ and aggressive humor $(\mathrm{M}=7.50, \mathrm{SD}=3.39)$ both significantly elaborated more ideas than non-humor $(\mathrm{M}=4.55, \mathrm{SD}=2.48)$ condition. Therefore, it can be summarized that affiliative humor and aggressive humor significantly produced more original, fluent, flexible, and elaborated ideas than the non-humor situation.

Table 2. One-way analysis of the variance of remote association task (RAT) and four dimensions of Alternative use of tasks (AUT) of non-self-involvement humor.

\begin{tabular}{|c|c|c|c|c|c|c|}
\hline & & $\begin{array}{l}\text { Sum of } \\
\text { squares }\end{array}$ & $d f$ & $\begin{array}{c}\text { Mean } \\
\text { square }\end{array}$ & $F$ & Sig. \\
\hline \multirow[t]{3}{*}{ RAT } & Between groups & 62.533 & 2 & 31.267 & 8.58 & 0.001 \\
\hline & Within groups & 207.650 & 57 & 3.643 & & \\
\hline & Total & 270.183 & 59 & & & \\
\hline \multirow[t]{3}{*}{ Originality } & Between groups & 84.933 & 2 & 42.467 & 8.64 & 0.001 \\
\hline & Within groups & 280.050 & 57 & 4.913 & & \\
\hline & Total & 364.983 & 59 & & & \\
\hline \multirow[t]{3}{*}{ Fluency } & Between groups & 80.033 & 2 & 40.017 & 13.83 & 0.001 \\
\hline & Within groups & 164.900 & 57 & 2.893 & & \\
\hline & Total & 244.933 & 59 & & & \\
\hline \multirow[t]{3}{*}{ Flexibility } & Between groups & 56.933 & 2 & 28.467 & 9.65 & 0.001 \\
\hline & Within groups & 168.050 & 57 & 2.948 & & \\
\hline & Total & 224.983 & 59 & & & \\
\hline \multirow[t]{3}{*}{ Elaboration } & Between groups & 156.033 & 2 & 78.017 & 8.29 & 0.001 \\
\hline & Within groups & 536.150 & 57 & 9.406 & & \\
\hline & Total & 692.183 & 59 & & & \\
\hline
\end{tabular}


The aim of this study was to examine the effect of other-related humor types such as affiliative humor and aggressive humor on individual creative thinking. To get the answer, researchers formulated two hypotheses. The first hypothesis was "H1: People who engage in affiliative humor would perform better at remote association tasks than aggressive or no humor."Results showed that people who engaged in affiliative humor perform better at remote association tasks than non-humor but not better than aggressive humor. Thus, our first hypothesis was partially supported by our result. Therefore, it can be said that affiliative humor successfully increased convergent thinking. This finding is in line with correlational research Lussiera et al.(11). Our result also showed that aggressive humor also increased convergent thinking instead of decreasing. This finding was inconsistent with the previous correlational study of Cayirdaga and Acarb (19). According to the generation and exploration model ${ }^{(22)}$ of creativity, this finding can be justified in a way that when affiliative humor is presented, the inconsistency or disagreement of affiliative humor may become a source of cognitive dissonance of engaged participants who consider and evaluate appropriate solution of remote association of task. Thus, participants in affiliative humor perform better at convergent thinking, which is not induced by the non-humor situation.

To investigate the divergent thinking, researchers hypothesized that " $\mathrm{H}_{2}$ : People who engage in affiliative humor would perform better at alternative use of task than people who engage in aggressive or no humor". Our result showed that people who engage in affiliative humor create more original ideas, fluently produce more ideas, showed greater flexibility in generating ideas, and those ideas are more elaborated than the non-humor group, which was also partially supported our second hypothesis and in line with Cayirdaga and Acarb ${ }^{(19)}$ and Chang et al.(12). Similar to affiliative humor, aggressive humor had an incremental effect on originality, fluency, flexibility, and elaboration components of divergent thinking. This finding contradicts(17) Kocak's (2018) finding and Cayirdaga and Acarb ${ }^{(19)}$, where they found aggressive humor was negatively related to creativity. Our findings are also inconsistent with the finding of some researchers ${ }^{(14,15,23)}$, where they found no relationship between aggressive humor and creativity.

It was indicated that affiliative humor and aggressive humor both help to increase divergent thinking. According to the generation and exploration model ${ }^{(22)}$ of creativity, affiliative humor may fuel the development of the mental representation of possible solutions and retrieval of the existing ideas from memory, which finally generate new original, fluent, flexible, and elaborated ideas in divergent thinking. However, the findings of this current experiment about aggressive humor consisted with the findings of Yue and Hui ${ }^{(18)}$ where they found aggressive humor positively related to creativity.

Above findings in convergent and divergent creative thinking of this present study revealed that not only affiliative humor but also aggressive humor increased convergent thinking which is inconsistent with a few traditional correlational research. There are 
some possible explanations for these inconsistent findings. First of all, the previous researcher considered aggressive humor as a personality trait in their correlational research. However, in real life, when a person engaged or experienced aggressive humor,that distracts a person sufficiently ${ }^{(24)}$ from the awareness of the implication of aggression. Thus, the person enjoys aggressive humor, as a result, increases creative performance. Secondly, when a person experiences aggressive humor, that may be considered a form of cognitive assessment, allowing an individual to perceive the potentially stressful events as more positive rather than threatening(25).As a result, aggressive humor increases rather than decreases divergent and convergent thinking. Finally, according to the human energy theory of Freud, the creative outcome is the byproduct of indirect expression of aggression energy ${ }^{(26)}$, and aggressive humor produces aggression ${ }^{(27)}$. Therefore, instead of decreasing, aggressive humor increases convergent thinking and divergent creative thinking.

Limitations: One of the limitations of this study, the researchers examined only two types of other-related humor. In future research, one could investigate other types of humor, such as eight comic styles of humor and their effect on creativity. Secondly, this research used only university students, where the author considered certain age groups. Nevertheless, in different life stages, the humor's pattern of physiological and psychological mechanisms has different characteristics. Thus, in the future, one could investigate including other age groups. Thirdly, the researchers used between-group designs in each experiment which require more participants. However, researchers used a small number of participants. If they were able to include more participants, that would increase the generalizability of this research's findings. Fourthly, the researchers conducted this experiment in developing countries and Asian cultures. Thus, the generalizability of this research's findings is limited to a particular culture. Finally, in this present study, the researchers only investigate individual creativity. So, in the future, one can examine the effect of other-related humor on collaborative or group creativity.

The objective of the present study was to identify the effect of other-related humor types on creativity. Participants engaged in affiliative and aggressive humor before the convergent and divergent thinking task in an experimental setting. The researchers obtained adequate information from our experiment that people benefited from both the affiliative humor and the aggressive humor in convergent thinking and four components of divergent thinking (originality, fluency, flexibility, and elaboration). This study extends the previous correlational research and is consistent with the previous correlational findings on the influence of affiliative humor on creativity but introduces a new approach to the literature on the influence of aggressive humor on creativity. 


\section{References}

1. Amabile TM 1983. The social psychology of creativity: A componential conceptualization. Journal of Personality and Social Psychology 45: 357-376.

2. Guilford JP 1967. The Nature of Human Intelligence. McGraw Hill: Harper \& Row. pp.538.

3. Kaufman JC and RA Beghetto 2009. Beyond big and little: The four c model of creativity. Review of General Psychology13(1): 1-12.

4. Hennessey BA and TM Amabile 2010. Creativity. Annual Review of Psychology 61(1): 569-598.

5. Peng J, G Zhang, Z Fuand Y Tan 2013. An empirical investigation on organizational innovation and individual creativity. Information Systems and e-Business Management.12(3): 465489.

6. Martin RA, P Puhlik-Doris, G Larsen, JK Gray and Weir K 2003. Individual differences in uses of humor and their relation to psychological well-being: Development of the humor styles questionnaire. J. Res. Personality 37(1): 48-75.

7. Miczo N, JM Averbeck and T Mariani 2009. Affiliative and aggressive humor,attachment dimensions, and interaction goals. Communication Studies 60(5): 443-459.

8. Martin RA 2007. The Psychology of Humor: An Integrative Approach. San Diego: Elsevier Academic Press. pp. 277.

9. Lu JG, AE Martin, A Usovaand AD Galinsky 2019. Creativity and humor across cultures: Where aha meets haha.In: Explorations in Creativity Research. San Diego, CA: Academic Press. pp. 183203.

10. Korovkin SY and OS Nikiforova 2015. Humor as a facilitator of insight problem solving Paper presented at: Euro Asian Pacific Joint Conference on Cognitive Science. Torino, Italy.

11. Lussiera B, Y Grégoirea and M-AVachonb 2017. The role of humor usage on creativity, trust and performance in business relationships: An analysis of the salesperson-customer dyad. Industrial Marketing Management 65:168-181.

12. Chang J-H, H-C Chen, C-C Hsu, Y-C Chanand Y-L Chang 2015. Flexible humor styles and the creative mind: Using a typological approach to investigate the relationship between humor styles and creativity. Psychology of Aesthetics, Creativity and the Arts 9(3): 1-7.

13. Lang JC and CH Lee 2010. Workplace humor and organizational creativity. The International J. Human Resource Management 21(1): 46-60.

14. Deog-Rolee 2015. The impact of leader's humor on employees' creativity: The moderating role of trust in leader. Seoul J. Business 21(1): 59-86.

15. Amjed Aand SHS Tirmzi 2016. Effect of humor on employee creativity with moderating role of transformational leadership behavior. J. Economics, Business and Management 4(10): 594-598.

16. Masih S, K Daniel, I Daniel, S Saher and A Hewawitharana 2020. Affiliative and selfenhancing humor in leadership and their relationship to employee well-being and creativity via lmx. Global J. Emerging Sci. 2(1): 35-55.

17. Kocak G 2018. The relationship between humor style and creativity: A research on academics. Eurasian Journal of Business and Management 6(4): 44-58.

18. Yue XD and ANHui 2015. Humor styles, creative personality traits, and creative thinking in a hong kong sample. Psychological Report 117(3): 845-855. 
19. Cayirdaga N and S Acarb 2010. Relationship between styles of humor and divergent thinking. Procedia Social and Behavioral Sci. 2(2): 3236-3240.

20. Svebak S 1996. The development of the sense of humor questionnaire: From SHQ to SHQ-6. Humor 9(3-4): 341-361.

21. Mednick SA 1968. The remote associates test. The Journal of Creative Behavior 2(3): 213-214.

22. Finke RA, TB Ward and SM Smith 1992. Creative cognition: Theory, research and applications. Cambridge: MIT Press.

23. Yonatan-Leus R, O Tishby, G Shefler and H Wiseman 2017. Therapists' honesty, humor styles, playfulness, and creativity as outcome predictors: A retrospective study of the therapist effect. Psychotherapy Res. 28(5):793-802.

24. Gollob HF and L Jacob 1967. Distraction as a factor in the enjoyment of aggressive humor. Journal of Personality and Social Psychology 5(3): 368-372.

25. Gemigni P 2012. Is humor the best medicine? Gremigni P. ed.Humor and Health Promotion. New York: Nova Science Publishers. pp. 149.

26. Kashapova MM, TV Ogorodovaa and SA Pavlovab 2016. Relationship between aggression and creativity in senior preschool children. Procedia - Social and Behavioral Sci. 233: 264-268.

27. Berkowitz L 1970. Aggressive humor as a stimulus to aggressive response. Journal of Personality and Social Psychology 16(4): 710-717.

(Manuscript received on 8 May, 2021; accepted on 25 November, 2021) 